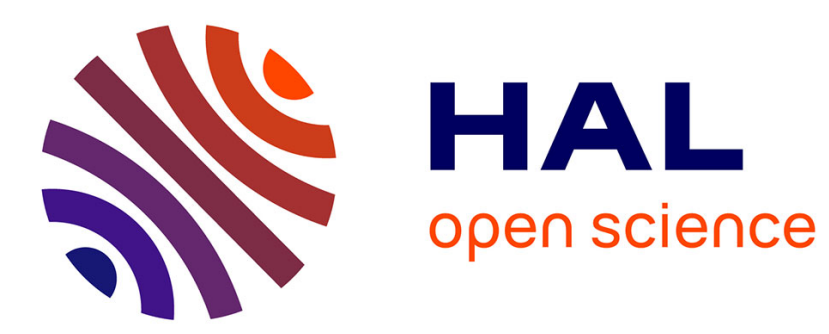

\title{
The role of biomass gasification and methanisation in the decarbonisation strategies
}

Gabin Mantulet, Adrien Bidaud, Silvana Mima

\section{To cite this version:}

Gabin Mantulet, Adrien Bidaud, Silvana Mima. The role of biomass gasification and methanisation in the decarbonisation strategies. Energy, 2020, 193, pp.116737. 10.1016/j.energy.2019.116737 . hal02418770

\author{
HAL Id: hal-02418770 \\ https://hal.science/hal-02418770
}

Submitted on 19 Dec 2019

HAL is a multi-disciplinary open access archive for the deposit and dissemination of scientific research documents, whether they are published or not. The documents may come from teaching and research institutions in France or abroad, or from public or private research centers.
L'archive ouverte pluridisciplinaire HAL, est destinée au dépôt et à la diffusion de documents scientifiques de niveau recherche, publiés ou non, émanant des établissements d'enseignement et de recherche français ou étrangers, des laboratoires publics ou privés. 


\title{
The role of biomass gasification and methanisation in the decarbonisation strategies
}

\author{
Gabin MANTULET $^{1,2}$, Adrien BIDAUD ${ }^{1}$, Silvana MIMA ${ }^{2}$ \\ ${ }^{1}$ Univ. Grenoble Alpes, CNRS, Laboratory of Subatomic Physics \& Cosmology IN2P3 (LPSC), F-38000 Grenoble, \\ France \\ ${ }^{2}$ Univ. Grenoble Alpes, CNRS, Grenoble Applied Economic Lab (GAEL), F-38400 Saint Martin d'Hères, France
}

November 2019

\section{Abstract}

The study explores future development of biomass uses across different climate policy scenarios and under different assumptions of biomass supply availability and technology performances. Broad bioenergy technology portfolios and generations provide flexibility to allocate bioenergy to supply a specific final energy mix and to remove carbon dioxide by combining bioenergy with carbon capture and sequestration (BECCS). The paper aim is to perform a detailed and focused analysis of the availability of biomass gasification and methanisation and the role of these green gas energy carriers in the decarbonisation strategies using a model based approach to see how some countries technology appropriation evolves through the $\mathrm{XXI}^{\mathrm{st}}$ century.

The results show that the future of bioenergy depends mostly on countries bioenergy supply and demand that are partly triggered by climate policies. Besides, very diverse local biomass end use patterns are highlighted depending on local resource availability, economic growth and climate policies. The majority of modern uses will be possible with a biomass transformation through the gas vector thanks to methanisation and gasification processes. Technology maturities and efficiencies are also essential for bioenergy development for the field competitiveness. In presence of climate policies, the deployment of biomass methanisation and gasification increases two or three times faster due to higher competitiveness compared to highly taxed fossil fuel. The possibility to implement CCS fosters even more the use of bioenergy for decarbonisation strategies in the long term and switching the allocation of the resource in favor of gasification with CCS.

Keywords: Long-term energy modelling, decarbonisation, bioenergy, gasification, methanisation, biogas, CCS, flexibility 


\section{Introduction}

Climate change is a major challenge to be urgently tackled nowadays and we aim at reducing human induced greenhouse gases (GHG) emissions because of global warming. The energy sector represents almost $80 \%$ of GHG releases, so that renewables and sustainable energy vectors have to develop massively to replace fossil fuels [1]. As well as known renewable energy as solar, wind or hydro, bioenergy represents a real feedstock for GHG emissions reductions. REmap 2030 from the International Renewable Energy Agency [2] shows the importance of bioenergy for meeting international targets for renewable share and for energy system decarbonisation, in particular bioenergy consumption should increase by $60 \%$ from 2015 to 2030 with climate policies implementation. Furthermore, bioenergy would play a major role in two of the three pillars in all deep decarbonization project scenarios [3] where bioenergy will reduce the carbon content of all transformed energies and will switch energy end-uses to lower-carbon, and even zerocarbon, energy carriers. While other renewables are only used to make green electricity, bioenergy can be used in lots of energy sectors: for electricity but also for liquid fuels, biogas, and hydrogen production. This flexibility makes bioenergy and bioenergy technologies valuable for the decarbonisation of energy use [1].

The official French Energy legal code specifies that: "Biomass is the biodegradable fraction of products, wastes and residues from agriculture, including plant and animal substances from the land and sea, forestry and related industries, as well as the biodegradable fraction of industrial and household waste" [4]. Bioenergy therefore means energy content in solid, liquid and gaseous products derived from biomass feedstocks including solid biomass, biofuels and biogas. Bioenergy is also a way to reach political objectives. For instance in the European Union, renewables have to represent $20 \%$ of the final energy consumption by 2020 (23\% in France) and 27\% by 2030 (32\% in France) [5]. Indeed, biomass is one of renewable and low carbon feedstocks that represents many sources of energy that are storable and compatible with many valorization processes. Its energetic valorization in electricity, heat, biogas or biofuel is compatible for different energy services, in which networks can be interconnected. Finally, yet importantly, considering the entire life cycle, bioenergy coupled with some carbon capture and storage (CCS) devices can bring negative carbon emission for energy systems, that is an efficient way to reach Paris climate accord' objectives [6].

Two different aspects come to the fore. The first one is the relevance of bioenergy valorization systems in energy supply compared to other sources of energy such as fossil fuels or renewables energies: what will be the share of bioenergy use in next decades? The second one is the energy technologies and conversion processes prioritization for biomass utilization: what will be the routes favoured and those neglected? Indeed, the diversity of biomass exploitation leads to competition among bioenergy value chains that depend on local parameters such as countries' biomass potential, economic growth, policies strategies, technologies maturities, etc. [6].

Only few research papers [7-10] or thesis works [11-13] address the role of pyrolysis, gasification, methanisation as independent decarbonisation options in prospective energy-modelling tools. This work will carry out a more detailed analysis on the local availability of biomass resource, the local bioenergy technologies appropriation and their role for achieving climate goals. The paper is structured as follows. Section two presents the main features of bioenergy and valorization technologies. Then we describe in section three the modelling in POLES and the methodology used. In section four, we present the analysis and local trends in bioenergy use. Section five summarizes the study and discusses further implications. 


\section{Biomass as a source of decarbonised energy and related gas valorization technologies}

The energy source tackled in this paper, biomass, is closely linked with gas energy carrier. Indeed, section 2.2. presents the technologies that convert biomass in bioenergy that produce gas. Gas, as an energy carrier, has two key strong point in order to reach global emissions reductions that are required to keep the rise in global average temperatures down to $2^{\circ} \mathrm{C}$ and to improve the world's air quality. First, versatility: gas can play multiple roles across the energy system in a way that no other fuel or technology can match. Gas can generate electric power, provide heat, and be used for mobility. Second, the environmental dimension: combustion of gas does produce some nitrogen oxides $\left(\mathrm{NO}_{\mathrm{x}}\right)$, but emissions of the other major sources of poor air quality, particulate matter and sulfur dioxide $\left(\mathrm{SO}_{\mathrm{x}}\right)$, are very tiny. The combustion of natural gas releases also approximately $20 \%$ less $\mathrm{CO}_{2}$ than oil, $40 \%$ less than coal by unit of energy and even well under half of what a coal plant emits with combined-cycle gas turbines by unit of electricity produced. As gas infrastructures and networks are well developed worldwide, this energy carrier would play a major role in energetic transition thanks to its storage capacity. Last but not least, gas-fired power plants also have technical and economic characteristics that are complementary with a strategy favouring the expansion of variable renewables with playing a lower carbon back-up role than coal or oil [14]. We will describe in this chapter the several type of biomass resource and the technologies, methanisation and gasification, that transform biomass into biogas.

\subsection{Biomass feedstock and conversion routes description}

Biomass feedstock is separated in three main categories [15]. First category gathers food production relative cultures: sugarcane, beetroot, corns, colza, maize, sunflower, palm or even soya. These resources aim at feeding the planet but are also convertible in biofuels as biodiesel for oil seeds and bioethanol for sugar seeds. Direct combustion and biofuel production are is their possibility of energetic valorization. Second category is referring to lignocellulosic resource: forests, plants for energetic purpose such as Miscanthus and agricultural wastes. Several energetic valorizations are possible: direct use as heat valorization, biofuels (Diesel Fisher-Tropsch and Ethanol) and electricity or gas conversion. This category of biomass will be the centre of the paper because of its high potential and advanced end-uses possibilities. Last feedstock is composed of algae and microalgae. For the moment, these conversion processes are only at an early step of R\&D. Their maturities are still limited compared to other generations, so that we will not discuss this resource in this paper.

All types of biomass use the $\mathrm{CO}_{2}$ in the air, in the soils, in the water in order to grow through photosynthesis process. Because this resource represents a way to store carbon, the main strength of biomass is the carbon neutrality. Even if there are some discussions about the real carbon content of the entire life cycle of biomass, it is common to assess that the carbon released during energetic valorization of biomass has been stored during its growth, so that the carbon footprint is lifecycle neutral or even negative with Carbon Capture and Storage (CCS) [15].

Figure 1 sums up the biomass feedstock feature, on the left, and the different routes and possibilities for energetic valorization. 


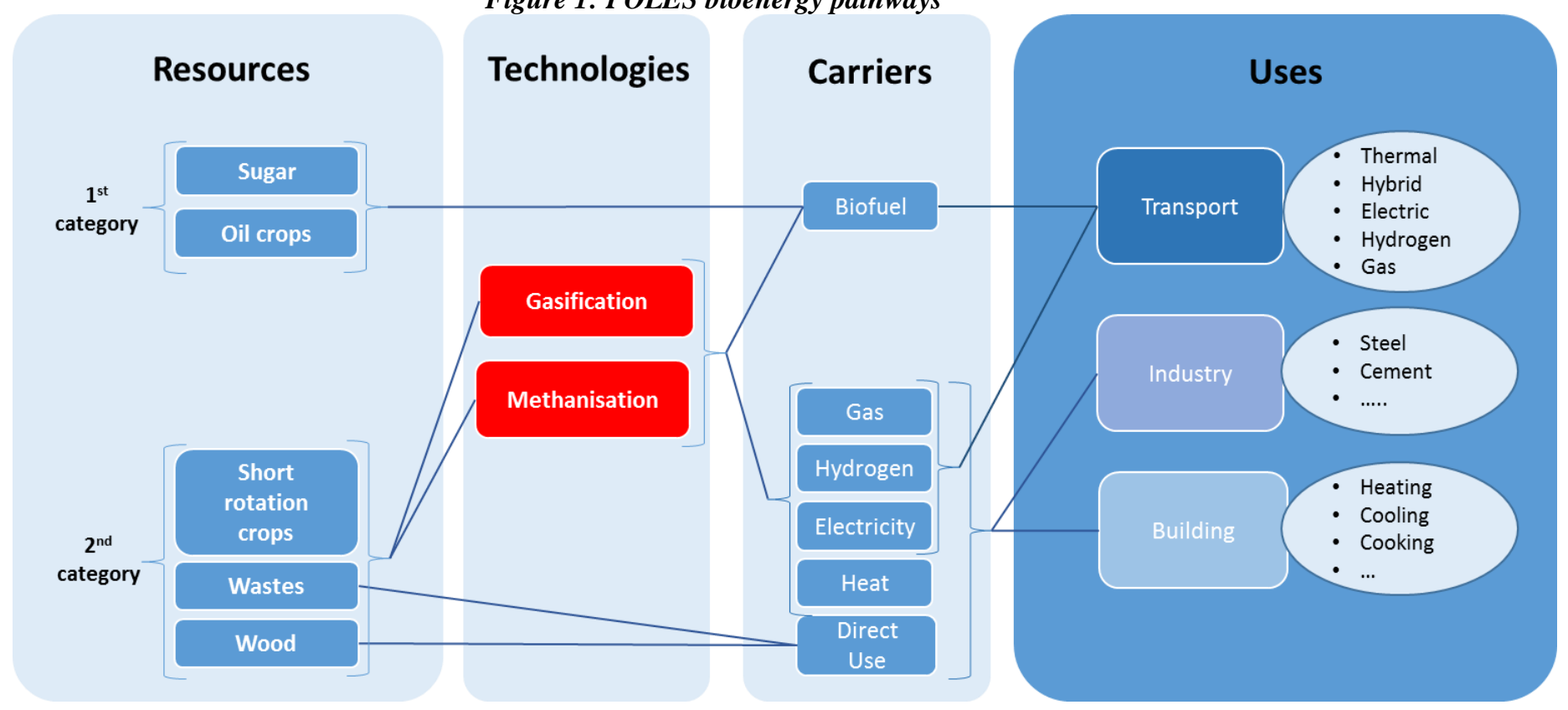

We describe briefly the main features for the two main energetic valorization paths for second-generation biomass that are considered in this paper: methanisation and gasification.

\subsection{Technologies consideration}

\subsubsection{Methanisation}

Methanisation, also called anaerobic digestion, is a biochemical process of biomass valorization into a gas mixture called biogas. Table 1 sums up the different methanisors design and the costs associated [16].

Table 1: Overview of methanisation installations

\begin{tabular}{|l|l|l|}
\hline \multicolumn{1}{|c|}{ Actors } & \multicolumn{1}{|c|}{ Inputs } & \multicolumn{1}{|c|}{ Construction cost (€/kW built) } \\
\hline \multirow{3}{*}{ Farms } & Vegetal, animal and sewage wastes & $\begin{array}{l}10000-15000(35 \mathrm{kWe}) \\
8600(170 \mathrm{kWe}) \\
5600(500 \mathrm{kWe})\end{array}$ \\
& Wood residues & $1700-2300$ in cogeneration \\
\hline Non-hazardous landfill & All wastes excepted electronics & $15000-76000$ \\
\hline Industries & Industrial wastes & $18000-42000$ \\
\hline Domestic wastes & Domestic wastes & $13000-20000(<10000$ habitants $)$ \\
\hline \multirow{2}{*}{ Water treatment plant } & Plant sludge & $3300-6600(>100000$ habitants $)$ \\
\hline Municipal wastes & Municipal wastes such as grass & $860-2000$ \\
\hline
\end{tabular}

It is worth noticing that the energetic yield for this bioenergy conversion from biomass to biogas is between $55 \%$ and $75 \%$ [15]. Nevertheless, other coproducts can be valorised, for example the solid residue called digestate into fertilizers, which can raise the global profitability of the process. While there are some technologies developments elsewhere (for example in Brazil and the USA), most of these developments are taking place in Europe, with Germany taking the lead. Since 2009, the amount of biogas plants in Europe grows by $20 \%$ per year on average. This number comes from 6227 in 2009 with 8,3Mtoe energy produced to 17376 (+279\% in 6 years) in 2015. Germany is the engine of Europe with 10846 plants installed in 2015, then Italy (1555 plants in 2015), France (717) and Switzerland (638) [16]. Figures are not consolidated for 2016 and 2017, but the number of biogas plants in Europe are raising a lot and policies objectives are high for 2020, 2023, 2025 or 2030 milestones in the decarbonisation strategies [17]. 
Nowadays, the major valorization after the biomass methanisation is a cogeneration with electricity and heat production from the biogas. However, this biogas can also be upgraded in biomethane after a methanation process in order to have a gas that can be injected in gas network, with an $80 \%$ lower carbon content than fossil gas [18].

\subsubsection{Gasification}

Gasification is a thermochemical conversion route for biomass valorization into a gas mixture called syngas [15]. Table 2 presents the different types of gasifiers with their features.

Table 2: Overview of gasification installations

\begin{tabular}{|l|l|l|l|}
\hline \multicolumn{1}{|c|}{ Type of gasifier } & Target size and applications & \multicolumn{1}{c|}{ Drawbacks } & \multicolumn{1}{c|}{ Advantages } \\
\hline $\begin{array}{l}\text { Downdraft }- \text { fixed bed reactor } \\
\text { (75\% of gasifiers installed) }\end{array}$ & $\begin{array}{l}\text { Small scales up to 1,5MW } \\
\text { Application : electricity }\end{array}$ & $\begin{array}{l}\text { Poor control of temperature, } \\
\text { mass and heat transfer } \\
\text { Inefficient char removal }\end{array}$ & $\begin{array}{l}\text { Simple and robust } \\
\text { Biomass flexibility in input } \\
\text { Low tars }\end{array}$ \\
\hline $\begin{array}{l}\text { Updraft - fixed bed reactor } \\
(2,5 \% \text { of gasifiers installed) }\end{array}$ & $\begin{array}{l}\text { Upper scales up to 2,5MW } \\
\text { Application : heat }\end{array}$ & $\begin{array}{l}\text { Poor control of temperature, } \\
\text { mass and heat transfer } \\
\text { Production of lots of tars }\end{array}$ & $\begin{array}{l}\text { Simple and robust } \\
\text { Biomass flexibility in input }\end{array}$ \\
\hline $\begin{array}{l}\text { Fluid bed reactor (20\% of } \\
\text { gasifiers installed) }\end{array}$ & $\begin{array}{l}\text { Medium scales up to 25MW } \\
\text { Application : electricity }\end{array}$ & $\begin{array}{l}\text { Biomass moisture } \\
\text { requirements } \\
\text { Ash management }\end{array}$ & $\begin{array}{l}\text { Efficient control of temperature, } \\
\text { mass and heat transfer } \\
\text { Easy to scale up }\end{array}$ \\
\hline $\begin{array}{l}\text { Entrained Flows Reactors : } \\
(2,5 \% \text { of gasifiers installed) }\end{array}$ & $\begin{array}{l}\text { Large scales up to 100MW } \\
\text { Application : liquid fuels }\end{array}$ & $\begin{array}{l}\text { Complex } \\
\text { Expensive }\end{array}$ & $\begin{array}{l}\text { Compact } \\
\text { No tars and char } \\
\text { Ash management }\end{array}$ \\
\hline
\end{tabular}

Biomass gasification plants are still in a demonstration point. Indeed, even if the energetic conversion yields are important, from $60 \%$ to $90 \%^{1}$ [18], some progress has to be done on the costs in order to be competitive: nowadays, costs raise approximately to $100000 €$ per $\mathrm{kW}$ installed that is at least ten times more than methanisors [19]. Europe and mainly Germany, the Netherlands and Northern countries are leaders with several demonstrators in progress such as Gobigas (20MW-installed power since 2014), bioSNG in Güssing, or Lahti Energy's Kymijärvi II [20-22]. Other countries are still in a RD\&D phase with demonstrators in construction or exploitation such as in France with Gaya or Futurol, etc. [23-24]. There are also some projects in the USA, mainly to produce biofuel [25-26], but also in China, India, Brazil or Canada [15].

\subsubsection{Complementarities}

The route of injection of synthetic biomethane from the gasification sector is aimed at the conversion of lignocellulosic dry carbon materials such as forest or agricultural residues as well as renewable recycled materials, by-products of waste treatment (sludge). It is generally not suitable for the recovery of materials with very high moisture content that are rather intended for the biomethane production by anaerobic digestion. These two processes are therefore complementary since they mainly use different inputs. In addition, it should be noted that methanisation could also use methanation as a downstream process, to recycle the $\mathrm{CO}_{2}$ contained in the biogas. It allows the production of a synthetic biomethane with a "renewable" carbon dioxide origin that can be added to gasification process.

\footnotetext{
${ }^{1}$ Biomass energetic conversion reach a yield between $60 \%$ for direct biomethane network injection and $90 \%$ with biomethane + heat production while biomass boilers have a energetic yield reaching $80-85 \%$
} 


\section{Methodology}

Our study aims at analyzing the availability of biomass resource and biomass valorization technologies gasification and methanisation and their role in the decarbonisation strategies using a model based approach. The model used is the Prospective Outlook on Long-term Energy Systems (POLES), developed by Enerdata, the European Commission Research Center and the CNRS, an academic research institute in France. POLES has a strong background in providing analyses in the area of climate change and energy. It was already used in many European studies such as the GECO reports from European Commission Joint Research Center [27], for Energy Modelling Forum studies [28] as well as for IPCC reports [29]. Actually, we can consider POLES as validated thanks to these previous recognized studies using this model and the constant effort to update POLES structure and data [30].

\subsection{The POLES bioenergy modelling}

The POLES model is a bottom-up long-term energy-modelling tool, seen as a partial equilibrium model. Bottom-up means that the energy demand is represented at a detailed level (equipment, uses, technologies, markets, etc.). It is a large-scale system where the world is divided in 66 regions. It aims at exploring long-term developments in energy systems until 2100 with a year-by-year simulation of supply, demand and price interactions. The modelling applies simulations with full interaction of demand and supply dynamics with price changes through lagged adjustments. POLES helps us to generate diversified energy scenarios and in particular to take full account of GHG abatement policies in a consistent economic framework (i.e. through carbon tax, emission quotas or regulation).

The model takes as input parameters: the projected population, Growth Domestic Product (GDP) by region, oil and gas resources, technology costs and performances. Then it provides as outputs the international and national energy prices, full IEA-type national energy balance with 13 final sectors, diffusion of about 30 key energy technologies. It details the energy model at world level with economic consistency provided by the central role of prices and technological change.

The biomass sub-architecture is detailed as follow. Each feedstock is represented and the potential assessed for each region is associated to a dedicated surface for culture, a harvesting yield, and a marginal cost curve. The combination of these parameters gives us the technical and economic potential for each feedstock for each region. Resource allocation is determined endogenously with a merit order algorithm where end-use needs are answered by minimizing the system cost where algorithm considers feedstock, trade, other resources' competition to fulfil requirements. It is worth noticing that biomass is allocated for energetic purpose without going into competition with food requirements and land sustainability. Therefore, biomass allocation will depend on its local yields and availability, on other resource prices, on the overall demand, on availability and cost of transformation processes (CAPEX and OPEX) and the expected R\&D progress. It is worth noticing that all these features depend on the region, the time and the scenario considered [30-31].

\subsection{Scenarios implemented}

We carry out some energy scenarios that span across XXI ${ }^{\text {st }}$ century. These scenarios are defined according to different political energy strategies that drive to different energy uses and energy mixes and their relative carbon emissions.

The scenarios study the sensitivity to several parameters. First, it's worth noticing that world population, growth domestic products, coal, oil and gas reserves and biomass potential come from International Energy Agency (IEA) [32] and GLOBIOM databases [33], so are taken into account exogenously in our scenarios. We propose two main scenarios: a baseline one that is the extension of actual energy policies, and the $2^{\circ} \mathrm{C}$ scenario that translates the application of climate policies aiming at limiting global warming under $2^{\circ} \mathrm{C}$ in 2100 , which is more stringent for $\mathrm{CO}_{2}$ releases. In this last scenario, a carbon tax is introduced so that prices are higher for energy vectors that release $\mathrm{CO}_{2}$ such as coal, oil or gas and their derivatives: gasoline, fuels, coke, etc. Hence, unlike fossil fuels, cleaner technologies that do not release GHG are fostered and their development speeded up. The goal is to respect the associated carbon budget $900 \mathrm{GtCO}_{2}$ eq releases until the end of the century for $2^{\circ} \mathrm{C}$ warming limitation.

Then a major sensitivity analysis is done. $2^{\circ} \mathrm{C}$ scenario is divided in two declinations, one with CCS technology and the other without. Indeed, and we will see it in the results presented section 4., the future of CCS deployment is the key 
parameter developing widely or not bioenergy or gas plants for decarbonisation, and more precisely lignocellulosic gasification: "All pathways that limit global warming to $1.5 \mathrm{C}$ with limited or no overshoot project the use of Carbon Dioxide Removal (CDR) on the order of 100-1,000GtCO ${ }_{2}$ over the $\mathrm{XXI}^{\text {st }}$ century" [1]. However, doubts remain about the economical profitability of CCS deployment because of concerns about $\mathrm{CO}_{2}$ storage sites feasibility, technologies costs and real potential of implementation [2] [34]. Moreover, low fossil fuels prices, current relative failure of $\mathrm{CO}_{2}$ quotas markets, local legislation, etc. do not send incentives for this field development [6].

Scenarios spread until 2100 where long-term effects are depicted. A strength of the study is the separation of the biomass valorization technologies in this long horizon time, so that we are able to determine the penetration rate of methanisation and biomass gasification. The strong point of the model is the endogenously consideration of bioenergy allocation paths, from potential to technologies so that results are well integrated. That is directly linked with demand and needs, end use competition for biomass resource and technological competition.

Outputs are declined for several perimeters: the world and some regional trends. We take into account several representative countries that drives bioenergy markets worldwide: the European Union, China and the USA as dynamic continent country with different growth rates and Brazil as a Southern country and as the leader of world biofuels with the largest biomass potential in the world. The potential of biomass used, the trade of the resource, the importance of each final use (electricity, heat, gas, biofuel) and the development of each technology tackled (gasification and methanisation) for the different time and land scales covered will be presented. We put all these results in comparison with the GHG emissions representing the climate paths chosen. We assume that $\mathrm{GHG}$ emission variations follow $\mathrm{CO}_{2}$ emissions variation that is a hypothesis already made by IEA [32] and Eurostat's [5].

\subsection{Scenario comparison}

At the beginning, we will compare results from POLES to World Energy Outlook (WEO) of IEA [32] and World Energy Council (WEC) scenarios [35] for the energy and bioenergy trends in the first part of the XXI ${ }^{\text {st }}$ century in order to have coherent order of magnitudes. The differences with our modelling and our study is the time scaling: our scenarios span across the entire XXI ${ }^{\text {st }}$ century until 2100 whereas others models look at the future until 2040 or 2050. Moreover, POLES has a deeper technological separation so that is useful to analyse precisely the technological development for bioenergy expansion. Last but not least, the regionalisation of POLES allows us to study and compare several regions of the world and the main trends in bioenergy development depending on land specificities. 


\section{Results}

\subsection{A growth of bioenergy potential and consumption in the $\mathrm{XXI}^{\mathrm{st}}$ century}

First, it is worth noticing that biomass potential is assumed independent of the climate scenario chosen. In reality, it is not entirely true because of different global warming in scenario that imply different effects on land available, yield that change the production: "[Global warming induces] highly penalized productions in the climates of low-latitude countries, whereas those of temperate climates could be slightly favoured, at least as long as the warming remains below $2^{\circ} \mathrm{C}$ or $3^{\circ} \mathrm{C}$. But beyond that, warming should also result in a drop in yields" [27]. Nevertheless, it is a correct assumption in order to compare the biomass consumption in regard of a global maximum potential. The biomass potential data come from the Global Biosphere Management Model (GLOBIOM) [33] developed by the International Institute for Applied Systems Analysis (IIASA), and provides for each year from 2000 to 2100 the yield for each biomass feedstock and crop, the land available for food and energetic cultures, etc.

4.1.1. Global trends and other models comparison: a consensus of increasing biomass consumption in climate policies scenarios

Overall biomass consumption triple from 2015 to 2050 and quintuple from 2015 to 2100 . A higher share of the potential is used from $23 \%$ in 2015 to the range $75 \%-85 \%$ according to the scenario considered in 2100 . Two main trends exist: the first generation consumption for energetic purpose decreases in the XXI ${ }^{\text {st }}$ century while second generation biomass consumption explodes. The first generation consumption reduction results from an increasing need for food production because of world demographic growth expected from 7.5 billion people today to 9.5 billion in 2050 and 10.5 billion in 2100. Hence, this competition decreases the potential and the controversial utilization of first generation biomass for energetic purpose. In the same time, we observe a linear increase in second-generation biomass consumption with a growth of the potential for short rotation crops for energetic purpose and a stable wood resource potential. Bioenergy contributes to climate change mitigation by replacing some fossil fuels uses in electricity, transportation or heat valorization by local resource [36]. In addition, biomass consumption is higher in $2^{\circ} \mathrm{C}$ scenario than in baseline because of $\mathrm{CO}_{2}$ emission limitation goals and so increasing need of fossil fuel substitution [37].

The three studies assess primary energy consumption and energy consumption from biomass in $2040^{2}$ and can be compared with 2015 (figure 2). Even if there are some differences, where POLES modelling gives a little bit more importance to bioenergy than other models, the order of magnitude is coherent for all scenarios conducted. While bioenergy consumption increases for all scenarios between 2015 and 2040, this growth remains limited for baseline. Coupled with the high increase in total energy consumption (around 40\% from 2015 to 2040), the share of bioenergy in energy mix moves back a bit for AIE and WEC and remains constant in POLES. Hence, bioenergy is just following the global consumption growth trend but does not play a substitution role in energy mixes that still relies on majority (about $75 \%$ ) on fossil fuels: oil, coal and gas. The trend is the opposite for climate policies scenarios. Although overall energy consumption increases when compared to today, the growth is $80 \%$ lower in climate policies scenarios compared to baseline due to stronger sobriety and efficiency policies applications. In the same time, bioenergy is higher in all models. Therefore, the share of biomass in the energy mix is more important in 2040 than in 2015 for the three models: there is almost the double share for biomass use in climate policies scenarios for each valorization compared to baseline. For example, bioenergy resource increases in share in electricity represents $2.1 \%$ of energy produced in 2015 to around $6.8 \%$ in 2040 in POLES and around 5\% for the others models. These figures highlight the substitution role played by biomass where fossil fuels are not anymore in majority in world energy mix for electricity, heat and fuels production and are partially replaced with bioenergy.

\footnotetext{
2 The time horizon took into account for comparison with the other models is 2040. Indeed, each study does not present its result for the same horizon, so that we have to take a reference where all three models propose quantified results. This milestone is valuable for analysis because effects of some climate policies and changes in energy paradigm can be seen and projected.
} 
Figure 2: primary energy and biomass consumption - WEC, IEA and POLES models comparison

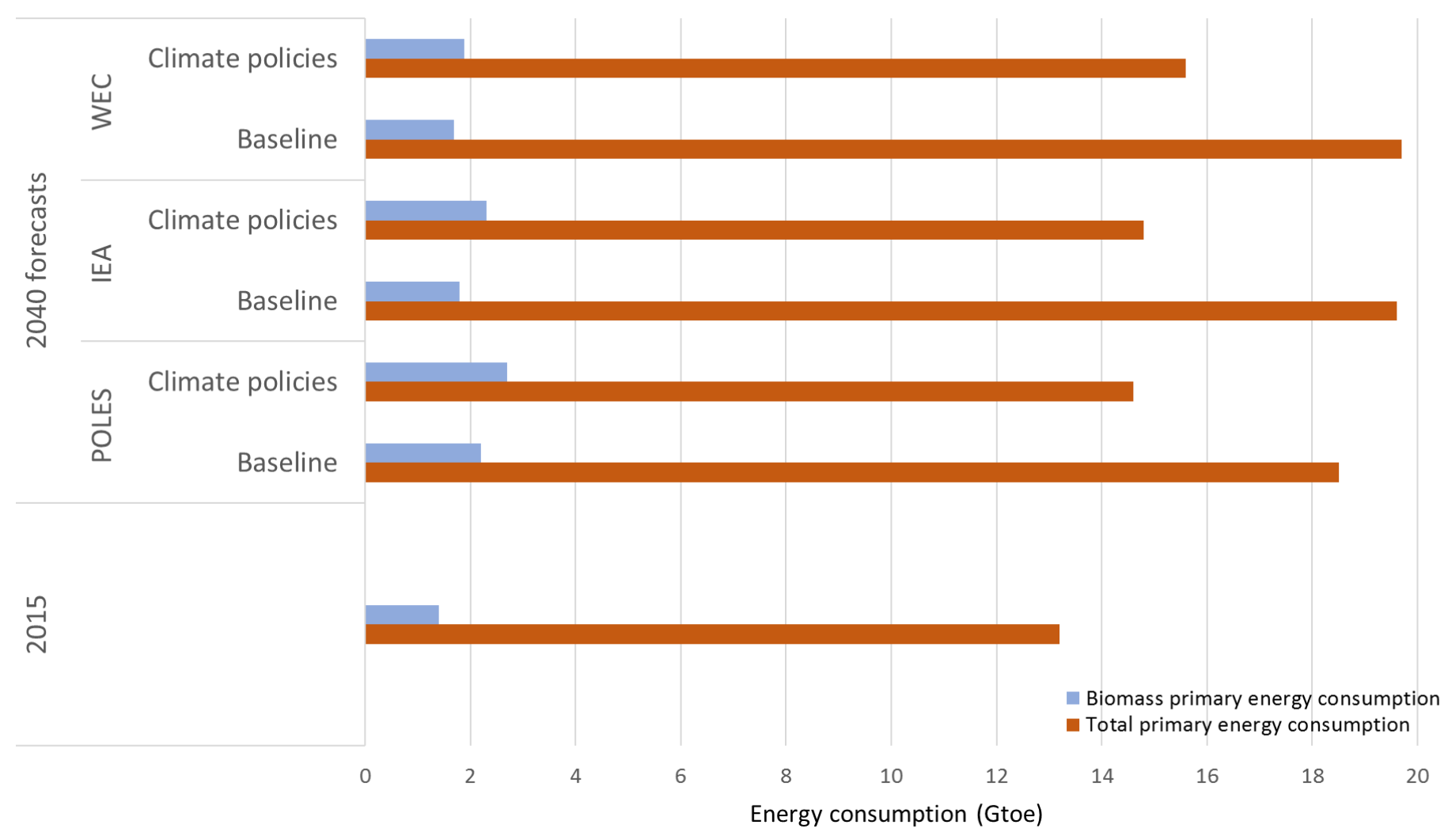

This allows us to validate our model compare to other well know economic models thanks to comparable outputs and future trajectories for each scenario. As seen in the IEA, WEC and POLES scenarios, bioenergies will play an expanded role in the energy mix in all scenarios with climate policies and a decreasing role in baseline scenarios with a massive use of fossil fuels, notably coal, in developing countries, which will represent the majority of the energy consumption growth. Let us consider now the several bioenergy uses and its global repartition.

\subsubsection{Different uses patterns depending on scenarios considered}

Heat is currently the main valorization for biomass because of a massive use of traditional combustion in the world. However, for 2050 and 2100, a growth in quantity and share for advanced valorization, electricity and secondgeneration biofuel, is highly expected. In the same time, traditional heat valorization is replaced by advanced heat valorization with higher performance index and less gas releases (figure 3). For instance, the efficiency of wood heating is very dependent on the technology used: efficiencies come from $10 \%$ for open fires to more than $90 \%$ for automatic boilers with platelets or pellets [38]. 
Figure 3: biomass potential and end-use consumption - world

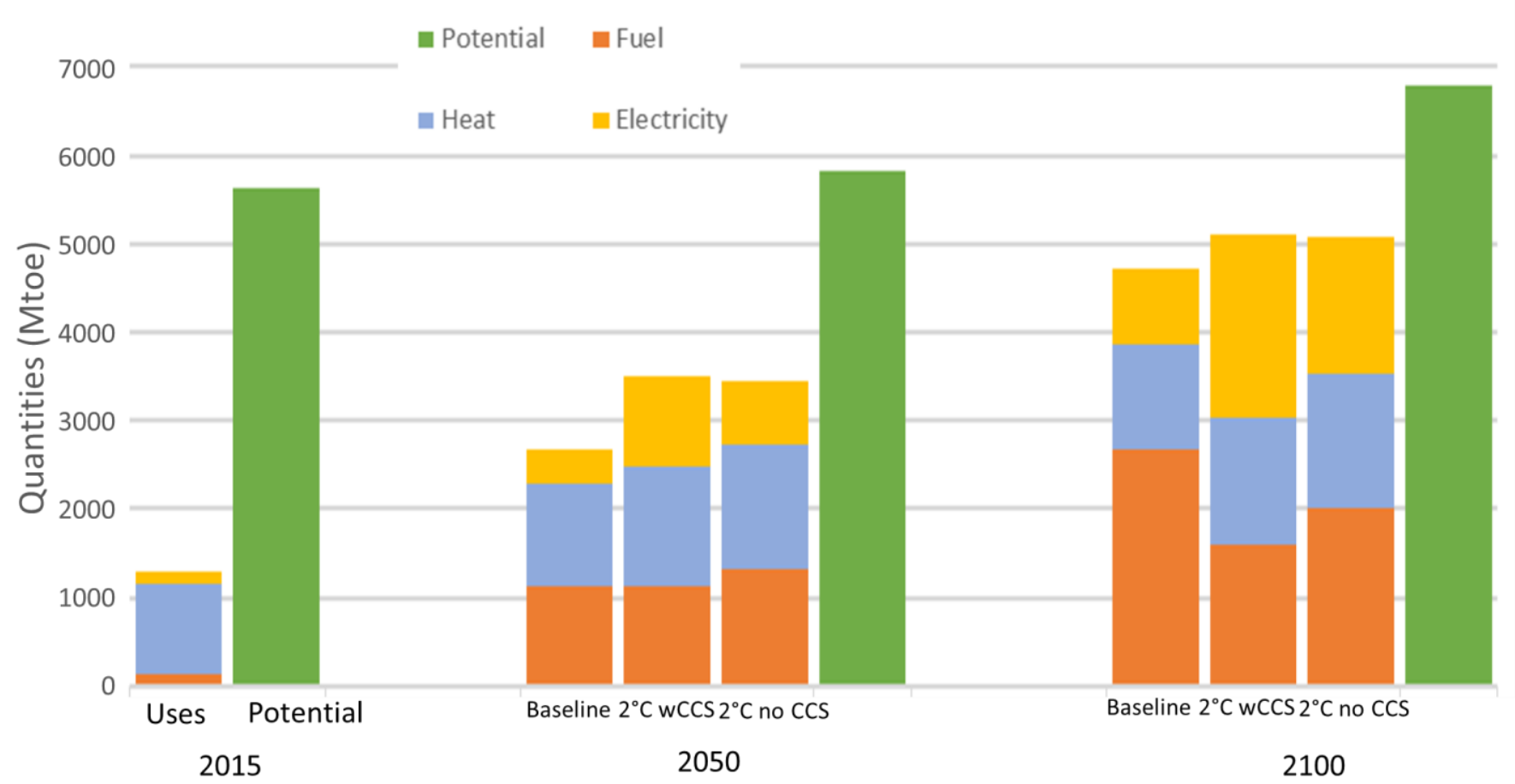

As mentioned previously, bioenergy consumption is higher in $2^{\circ} \mathrm{C}$ scenario. For a same potential and feedstock, a different repartition of resource valorization is observed. Indeed, a larger quantity of electricity is produced with biomass in $2^{\circ} \mathrm{C}$ scenario where climate policies and emissions reduction goals speed up the end use electrification, the replacement of electric generation from coal, oil and natural gas and reduce the overall fossil fuel consumption for transportation. Besides the possibility to add carbon capture and storage facilities with electricity generation would accelerate the decarbonisation of electric sector, so that BECCS implementation is largely done and increase electrical production from biomass in the $2^{\circ} \mathrm{C}$ scenario with CCS.

\subsubsection{Bioenergy triggers non-negligible reduction on $\mathrm{CO}_{2}$ releases}

Measures and technological choice taken in climate policies scenarios aim at limiting global warming by reducing greenhouse gases emissions. Without climate policies, the model project $3200 \mathrm{GtCO}_{2}$ cumulatively emitted in the rest of $\mathrm{XXI}^{\text {st }}$ century. Limiting these emissions to 1600 or 900 or even $400 \mathrm{GtCO}_{2}$ to avoid passing 3 or 2 or $1,5^{\circ} \mathrm{C}$ warming is very challenging. According to the majority of climate scientists and scenarios, "Two degree climate target [are] not possible without "negative emissions"” [28] [39]. Modelling allows quantifying this reduction. In our study, while $\mathrm{CO}_{2}$ emissions are growing up from $32 \mathrm{GtCO}_{2}$ in 2015 to $40 \mathrm{GtCO}_{2}$ until 2050 and stabilize in baseline until 2100, they are decreasing after 2025 and passing under zero after 2060 in $2^{\circ} \mathrm{C}$ scenario with the possibility to add CCS technology (figure 4). The drop is more pronounced in the scenario without CCS in which carbon neutrality is required early, in 2050, because of no possibility to overshoot the warming limit without the use of BECCS and related negative emissions possibilities [29].

POLES modelling allows a separation of the causes of the $\mathrm{CO}_{2}$ releases. We see the contribution of bioenergy and the contribution of CCS devices in the effort for $\mathrm{CO}_{2}$ reduction (figure 4) in aggregate world emissions. Bioenergy uses by decarbonising uses thanks to fossil fuels substitution allow a $\mathrm{CO}_{2}$ emissions reduction up to $25 \%$ achievable in 2100 . CCS allows also a smoother $\mathrm{CO}_{2}$ emission decrease, so a lower effort for world population in future years, but it requires a $\mathrm{CO}_{2}$ net capture up to $20 \%$ of current emissions level after 2060 . 
Figure 4: World $\mathrm{CO}_{2}$ emissions for the 3 scenarios considered, and the contribution of bioenergy and CCS in decarbonisation

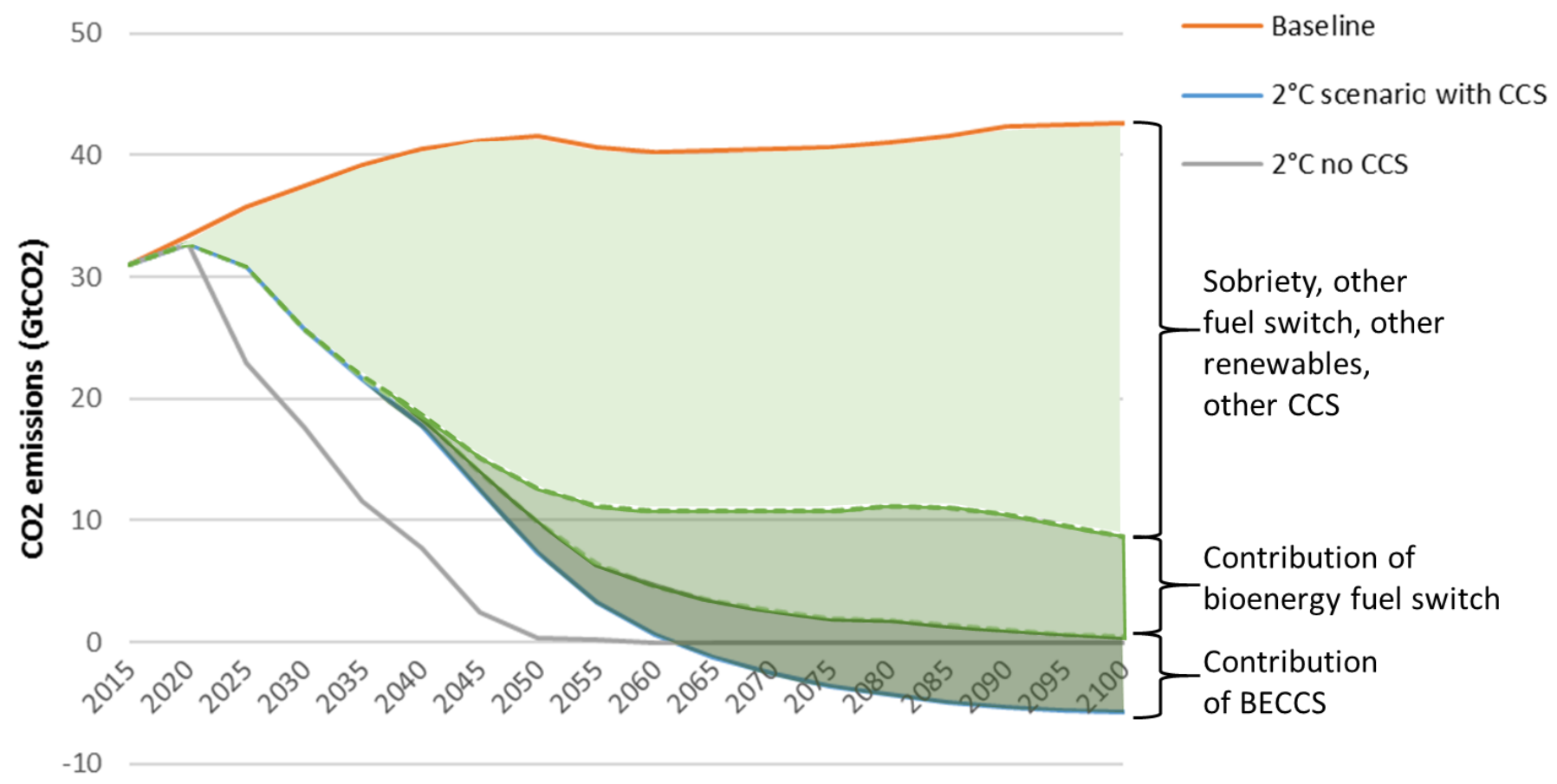

Therefore, bioenergy develops largely and, combined with CCS, it gives a $\mathrm{CO}_{2}$ emission reduction feedstock up to one third of actual world $\mathrm{CO}_{2}$ releases. Because of their massive consumption, continent countries with dynamic economic activity are the key actors in GHG emissions, but also for large-scale development of CCS to provide large emission reduction: the USA, China and India represent half of the world $\mathrm{CO}_{2}$ captured with bioenergy potential. The European Union, Gulf countries and South Africa are the other main contributors for $\mathrm{CO}_{2}$ sequestration all around the world.

\subsection{The different regional biomass allocation patterns}

As seen in section 4.1., biomass potential is widely used throughout the $\mathrm{XXI}^{\text {st }}$ century. Nevertheless, this global growth is not representative for each country of the world: each country has its own behaviour in biomass potential use.

4.2.1. The use of local potential: some countries use their entire potential, others not

The biomass potential use in 2015 is shown on figure 5. This graph shows the repartition of the regions that use a particular percentage of their potential. For instance, 11 regions use between $0 \%$ and $5 \%$ of their bioenergy potential in 2015 , and none use more than $75 \%$ of their potential. The average is about $25 \%$, but some countries as China are already using more than $2 / 3$ of their potential when others, such as Brazil or Russia, are using only very few percent of it. Hence, we can say that countries that are using the most of their potential nowadays is countries with low amount of potential compared to their needs.

However, world bioenergy use has increased and reaches $59 \%$ of the potential in baseline, $68 \%$ in $2^{\circ} \mathrm{C}$ scenario without CCS and $72 \%$ with CCS in 2050 . We observe a higher biomass consumption in climate policies scenarios. Moreover, the spread of countries is lower: all countries use a higher share of their resource, between $45 \%$ and $85 \%$. Some countries even saturate their potential by exploiting more than $90 \%$ of their resource. In 2100 , we observe the same evolution of the trends highlighted before: global potential used has increased again and reaches $75 \%$ in baseline, $84 \%$ in $2^{\circ} \mathrm{C}$ scenario without CCS and $76 \%$ with CCS (figure 5). The evolution and the increase of biomass potential use is smooth in the $\mathrm{XXI}^{\mathrm{st}}$ century. 


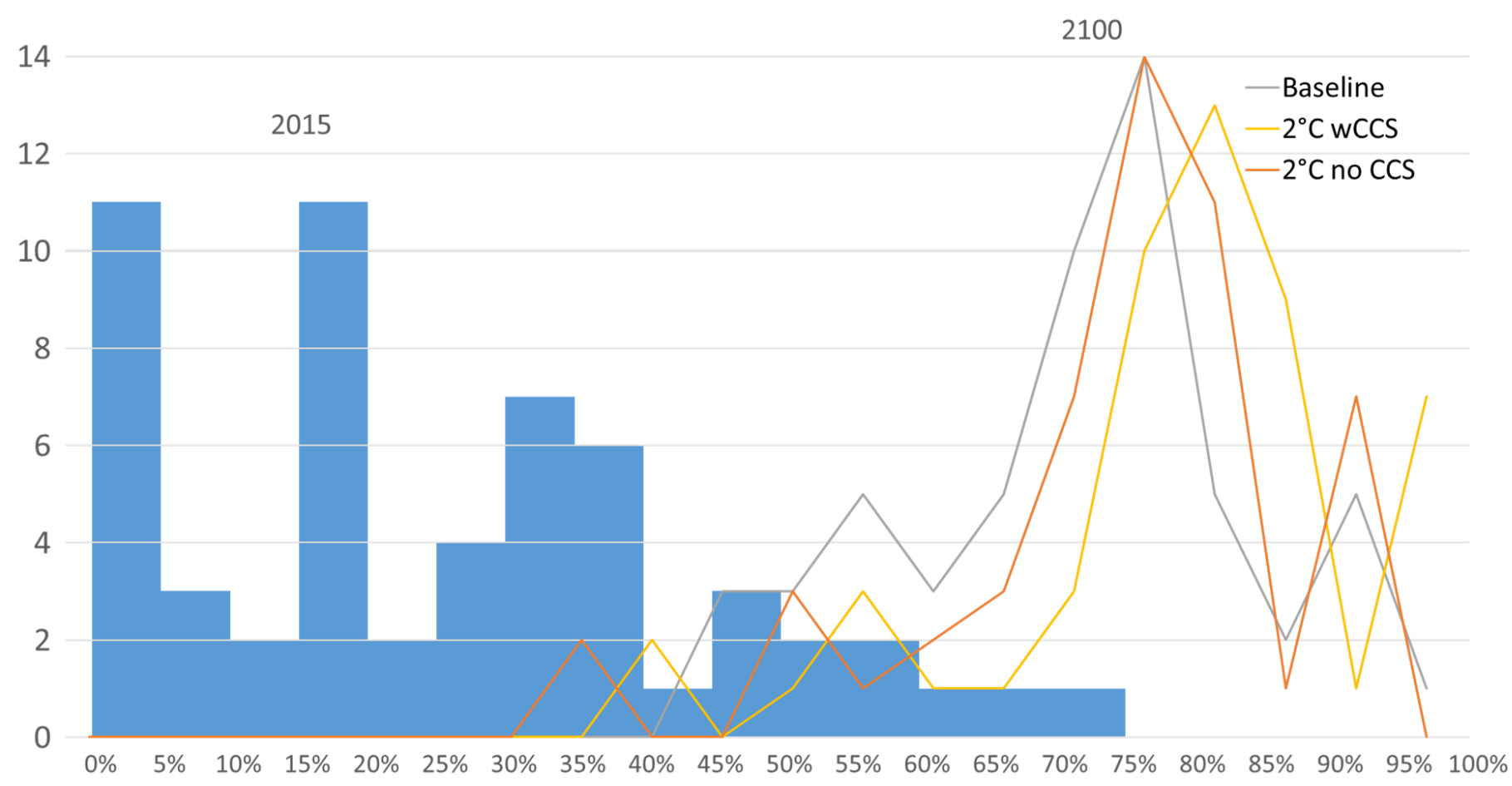

Nevertheless, it's worth noticing that Brazil, the principal exporter in XXI ${ }^{\text {st }}$ century, has a typical behaviour because it doesn't use a massive proportion of its potential in 2050 (between $40 \%$ and 55\%) and the growth is very high until 2100 (between $70 \%$ and $80 \%$ ). Although Brazil increases self biomass consumption, this increase is due to the largest potential of the world and the increasing need for trade in the second part of the century.

\subsubsection{The trade of bioenergy: biomass markets driven by few countries}

After having highlighted the potential used throughout the world, let us consider the relatives trade concerns. Indeed, as some countries saturates almost their potential, they need to import the resource to fulfil their needs from the main biomass producers. Besides, some countries have huge quantities of resource, so that they can valorise it on the international markets at high prices.

In 2015, only few countries traded noticeable amounts of resource up to 0,5Mtoe. Only few actors are actives for large quantity of biomass trade: Brazil, Australia, Russia and Canada for exportation, and China, India and the USA for importation. The vast majority of countries have a negligible trade balance compared to these countries.

However, the development of modern valorization of biomass drive a huge increase in bioenergy consumption, (see part 4.1.). Larger quantities are traded on the markets with an increase through the $\mathrm{XXI}^{\text {st }}$ century: quantities are multiplied by 10 in 2050 and again doubled in 2100 (figure 6). Our results show that the trends are conserved: the evolution of quantities traded are more or less linear for both importers and exporters. The same actors are the main contributors of bioenergy markets. However, while some countries had some negligible exports in 2015, we see that in 2050 and 2100 only the four main exportation countries are still exporting, in larger quantities. The others have almost saturated their potential and it is more cost effective to be supplied by foreign sources. 
Figure 6: Repartition of principal actors on biomass markets - 3 scenarios ranges

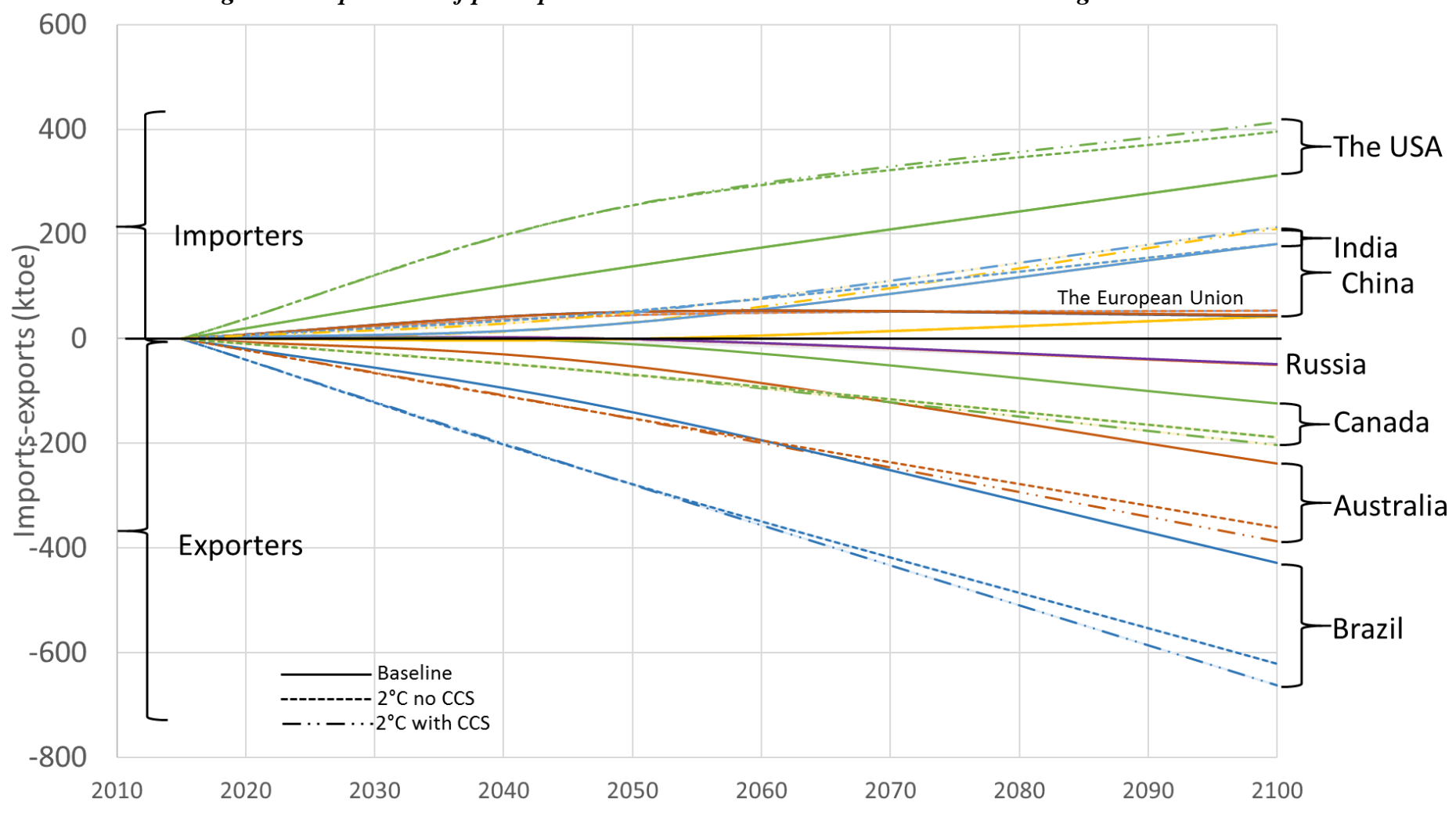

4.2.3. The technologies installed: more gasification in climate policies and with CCS possibilities

The conversion of biomass resource into energy tackles methanisation and gasification processes. Depending on the date and local particularities, these technologies are not developing at the same rate.

In 2015, gasification is still in a R\&D process, so that it is not developed worldwide. Methanisation represents the main technology installed to have a modern biomass valorization in energy. Nevertheless, thanks to some demonstrators, gasification will appear at the end of 2020s and will develop largely in the second part of the century [40]. The strong point of gasification is also to implement some CCS devices on factories so that net negative emissions can be reached.

Hence, at the end of the century, there is two main differences between baseline and $2^{\circ} \mathrm{C}$ scenario (figure 7). The first is the total installed power for bioenergy conversion that can triple in climate policies scenarios compared to baseline, that underline the importance given to biomass energy conversion in climate policies scenarios. Besides, while baseline drives to an installed power equivalent between methanisation and gasification plants, gasification is overriding with a mean of installed power that is ten times as much as methanisation in a climate constraint scenario. This trend is also accentuated with the possibility to add CCS because of these negative emissions well. 


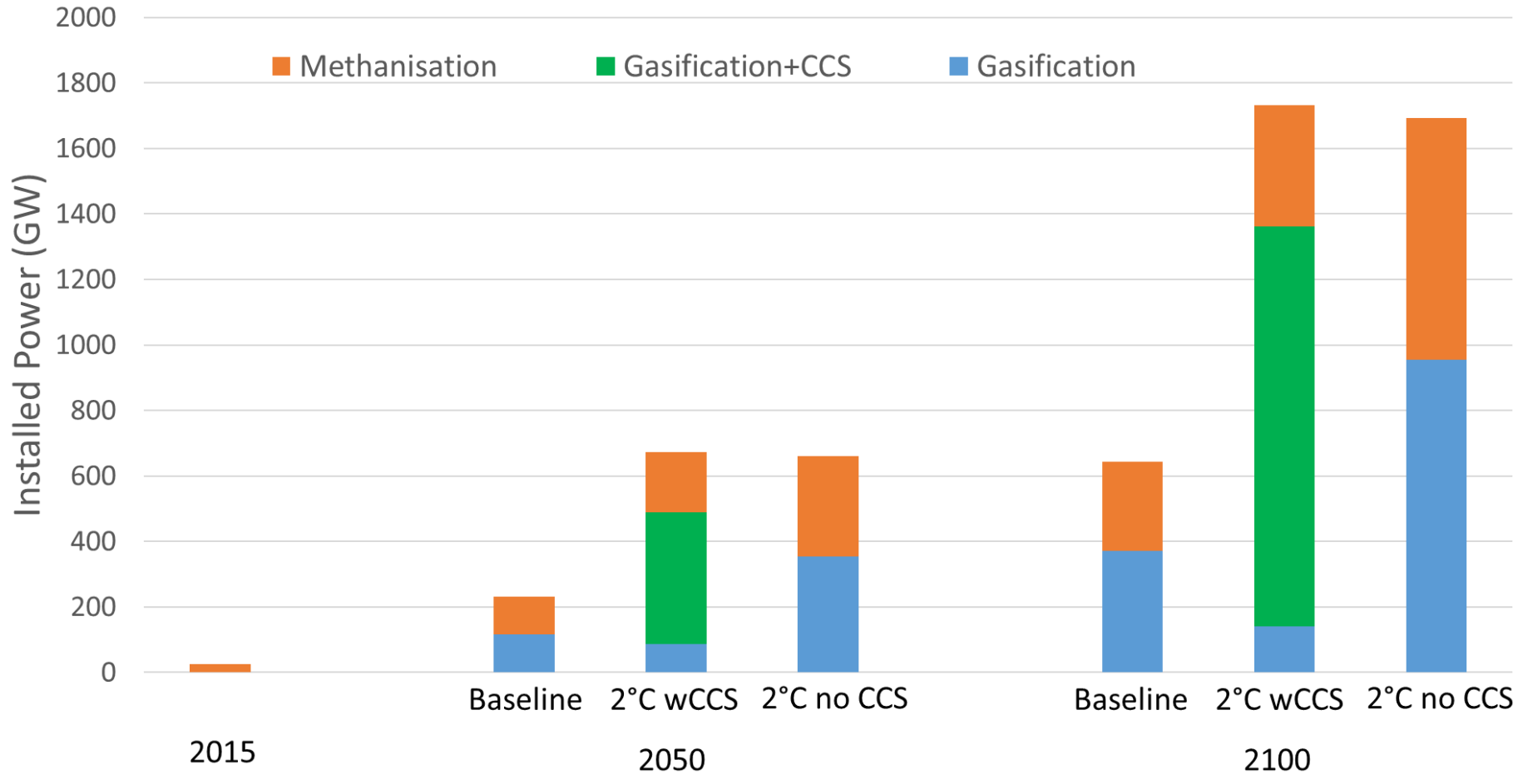

4.2.4. The repartition of the consumption: climate policies increase biomass-based electricity production

Last, after biomass having an energy transformation process, the bioenergy produced is allocated for electricity production, biofuels and for heat valorization. In 2015, the valorization of biomass in mainly through heat and marginally in electricity. By seeing the XXI ${ }^{\text {st }}$ century evolution (figure 8), three main points can be underlined. The first one is the decrease of the heat biomass valorization from $80 \%$ on average in 2015 to $30 \%$ on average in 2100 for all scenarios. This is due to higher added value with an electricty or biofuel valorization with the possibility to decarbonise these fields. We also observe the prominence of electricity use in climate policies scenarios and the prominence of biofuels transformations in baseline. Last but not least, we can see a large spread of the different consumptions for world countries. To sum up, we see a larger amount of electricity or heat in northern countries and a larger part of biofuel use in developing countries. 
Figure 8: The world repartition of bioenergy uses

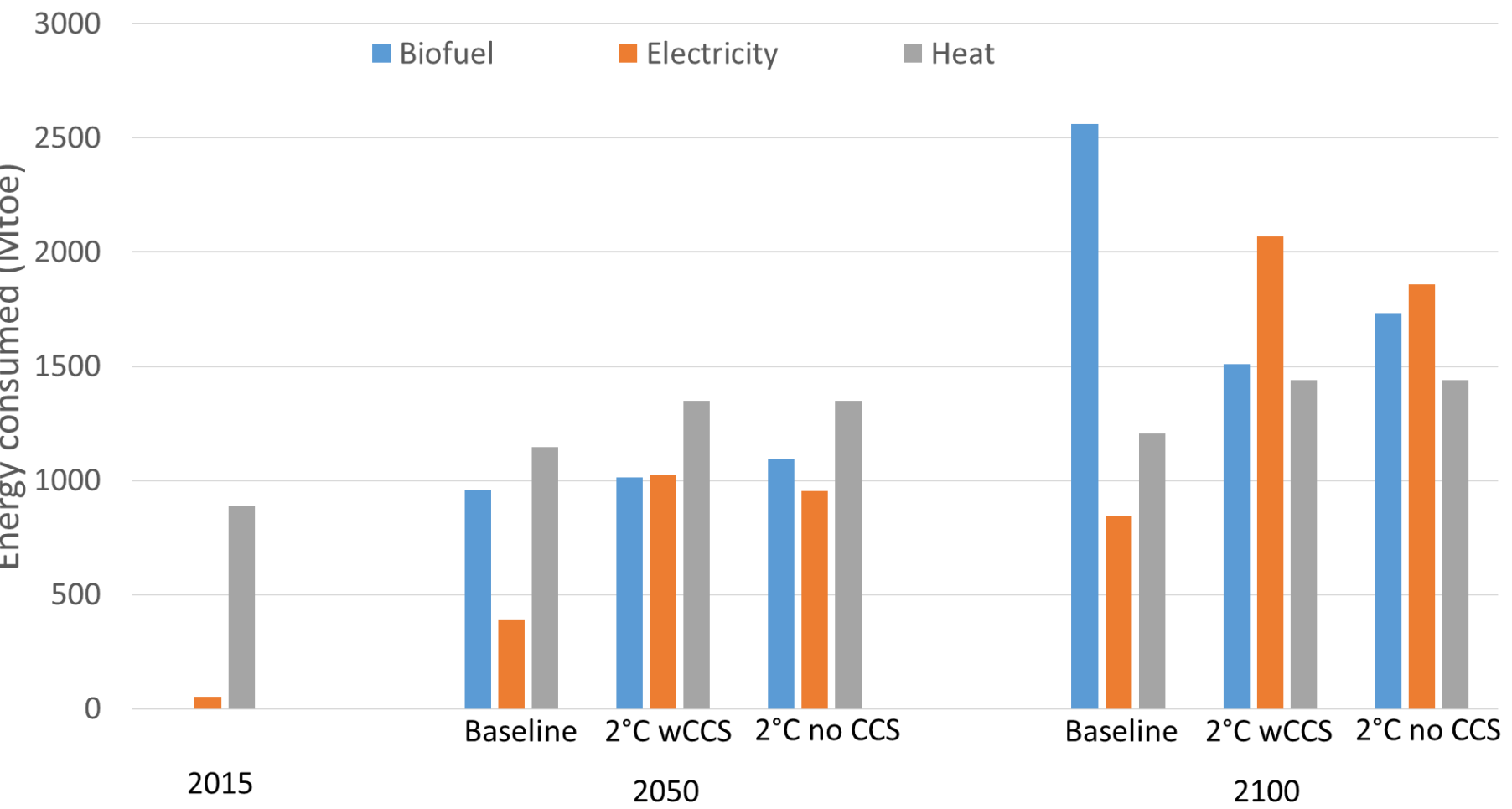

\subsubsection{Differences between continent countries: an illustration with a Sankey diagram}

As a summary, we can also represent in a Sankey diagram biomass energetic valorization for three important countries in 2100 (figure 9): the USA, China and Brazil, whose bioenergy consumption are respectively around 430Mtoe per year for Brazil, 420Mtoe for the USA and 530Mtoe for China. We see very different profiles of bioenergy consumption at the end of the century. As already said, biofuel strategy for Brazil and southern countries and electricity (dominant in China) or heat (dominant in the USA) for northern countries are specific to national contexts. Also we observe different ratios of technologies installed: 66\% more gasification than methanisation in the USA, 50\% more gasification in China but even the same amount in Brazil that is explained by the local context (resource availability, technology maturity, end-use need, etc.) that favor methansiation development. Concerning bioenergy patterns in 2100, modern valorizations of biomass are widespread even in baseline scenario where bioenergy is less developed. End use prioritization depends also on the local markets needs.

Figure 9: Sankey diagram, biomass use in 2100 - baseline - China, the USA and Brazil
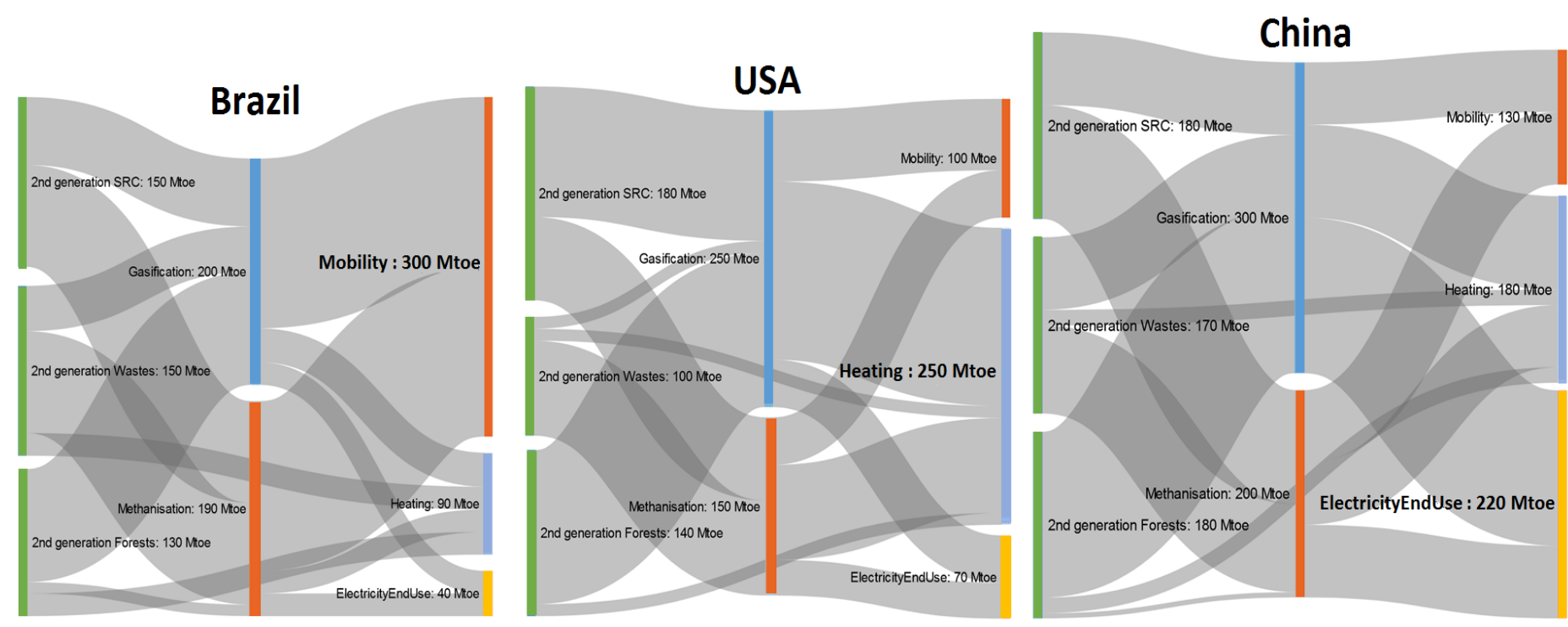


\section{Conclusions}

As solar, wind or hydro do not represent a silver bullet everywhere, there is no doubt that different types of biomass valorization such as direct use for heat and electricity or transformation in gas or biofuel is becoming more and more attractive for energy systems need decarbonisation coupled with flexibility. The environment of energy conversion routes is complex but the capture of interactions, complementarities and competitions between bioenergy processes and other energy technologies is a clue to better assess the future energy mix in line with the need of climate change stabilization [41].

POLES scenarios show that bioenergies will develop in all scenarios but with very different patterns as a function of country specificities and climate policies implemented. A larger part of the bioenergy potential from $25 \%$ in 2015 to 75 $85 \%$ in 2100 is used worldwide whatever the assumptions. To go further, the amount of biomass used is multiplied by 5 from 2015 to 2100 in climate policies scenario. Hence, biomass is more used for decarbonization purpose. Secondgeneration biomass valorization plays a major role in electricity and fuels conversion especially with high value of carbon tax that penalise fossil fuels. At a local scale, we highlight that electricity and heat valorizations are prominent in northern countries while biofuels are prominent in developing countries that underline the different rates of development and the different needs each region has. Bioenergy penetration speed and rate depends on resource potential and technology maturities and cost effectiveness. Therefore, methanisation develops earlier than gasification because the process is more developed and (almost already) profitable. Nevertheless, gasification catches up methanisation thanks to a high resource potential and process progress expected in R\&D. Hence, it will be used at the same order of magnitude in the second part of the century and even more in the presence of climate policies incentives and competitive CCS that are in development stages today. As seen in the last part of the analysis, CCS are becoming very important with high carbon constraints for technologies competitiveness in decarbonisation strategies. If BECCS are implemented widely, it will represent a key technology that generate negative emission needed for reaching climate commitments and would be massively used. Biomass methanisation and gasification will play an important role in future energy mixes bringing more stability and flexibility to the system and are complementary with variable renewable energies.

These two technologies enlarge the scope of flexibility brought by biomass to the gas vector [42]. Indeed, these processes convert biomass, which is a renewable, carbon-neutron source of energy, into a gas mixture that represents the new energy carrier. Then gas mixture from methanisation and gasification is transformable into heat, electricity or both or can be upgradable in biomethane for gas network injection with similar efficiencies. Yet, gas represents a good transition energy in order to reduce oil and coal use that can be stored more easily than electricity. It produces less local air pollution and the resource is cheap nowadays. Finally yet importantly, it is economically competitive for heating and electricity production as well as for mobility [43]. Furthermore, this energy vector may be central in energy transition, as its production based on biomass could be completed with power to gas ( $\mathrm{P} 2 \mathrm{G})$. This other green gas process uses an electrolyser and convert water in dihydrogen thanks to electricity. $\mathrm{H}_{2}$ is then upgradable in $\mathrm{CH}_{4}$ thanks to methanation [44]. Only few R\&D demonstrators are in preliminary phase nowadays [45]. Although technical potential for this resource is estimated low in 2035 because of low level of maturity and insufficient VRE penetration, P2G is a way to store electricity surplus in the gas network. It would be very useful and competitive when VRE share will be important in connecting electricity and gas networks in order to avoid electricity curtailment [46].

However, large uncertainties concern $\mathrm{CO}_{2}$ emissions and costs for technologies aiming at decarbonising gas network. Indeed, estimations vary from $-371 \mathrm{gCO}_{2 \mathrm{eq}} / \mathrm{kWh}$ to $642 \mathrm{gCO}_{2 \mathrm{eq}} / \mathrm{kWh}$ for green gas production from biomass, with an associated technological cost between 50€/MWh and 200€/MWh [47-48]. These figures depend on the scope taken into account in the assessment (for example the perimeter of life cycle analysis for bioenergy $\mathrm{CO}_{2}$ releases estimation), the type of technologies tackled, the localisation, R\&D and maturity hypothesis, etc. Moreover, costs for equipment and network needs for adaptation are also uncertain. For example, it is hard to consider what will be the cost for the gas network to switch from a fossil fuel supply to a green gas supply with the possibility to build some devices such as electrolysers only dedicated to produce green gas. Hence, even with our scenarios and hypothesis, competitiveness, future development and deployment for these energetic routes are almost unpredictable precisely [49]. At the end, "technology is not enough", because the field competitiveness in decreasing $\mathrm{CO}_{2}$ emissions depend a lot of the behaviour of people for technology use. Besides, negative side effects for bioenergy can slow the development of 
associated technologies where methanisation and gasification plants can raise concern for local population. They could be afraid of noise, smell, explosion risk, increase of traffic to fuel digesters, flies invasion, etc. All in all, a better communication about the characteristics of these technologies and how is it implemented in lands is key to remove concerns and to launch these fields at a bigger scale.

\section{Acknowledgments}

Funding for this research was provided by a grant from Carnot Energies du Futur. 


\section{References}

[1] IPCC, "Global warming of $1,5^{\circ} \mathrm{C}$ ", 2018, available online: https://www.ipcc.ch/report/sr15/

[2] International Renewable ENergy Agency, "REmap 2030 a renewable energy roadmap“, June 2014

[3] Deep Decarbonization Pathways Project, "Pathways to deep decarbonization 2015 report", 2015, SDSN - IDDRI, available online: http://deepdecarbonization.org/ddpp-reports/
[4] Code de l'énergie
français,
Articles
D211-1
D211-4,
available
online:

https://www.legifrance.gouv.fr/affichCode.do?cidTexte=LEGITEXT000023983208\&dateTexte=vig

[5] European Environment Agency, “Annual European Union greenhouse gas inventory 1990-2015 and inventory report 2017 Submission to the UNFCCC Secretariat". § 3.1, p.87, 2017

[6] IEA, "Energy Technology Perspectives 2017: Catalysing Energy Technology Transformations", chapter 7: Delivering sustainable bioenergy, June 2017, 315-360 p., available online: https://www.iea.org/bookshop/758-Energy Technology Perspectives 2017

[7] LONG H and al, "Biomass resources and their bioenergy potential estimation: A review", College of Resources Science and Technology, Beijing Normal University, available online 25 June 2013.

[8] DONG J \& al, "Life cycle assessment of pyrolysis, gasification and incineration waste-to-energy technologies: Theoretical analysis and case study of commercial plants.", june 2018

[9] MATHIOUDAKIS V and al., "The water footprint of second-generation bioenergy: A comparison of biomass feedstocks and conversion techniques", Journal of Cleaner Production, 2017, $\mathrm{n}^{\circ} 148$, pp571-582

[10] CHEN Q and LIU T, "Biogas system in rural China: upgrading from decentralized to centralized?", Department of Economic and technological Change, Center for development research (ZEF), University of Bonn, Germany, available online 11 May 2017.

[11] POZZOBON V, "Biomass gasification under high solar heat flux", Ecole des Mines d'Albi-Carmaux, 2015.

[12] HORTON S-R, "Modelling municipal solid waste gasification: molecular-level kinetics and software tools", Faculty of the University of Delaware, 2016

[13] BOILER GORLING M, "Energy system evaluation of thermo-chemical biofuel production: Process development by integration of power cycles and sustainable electricity”, KTH, School of Chemical Science and Engineering (CHE), Chemical Engineering and Technology, Energy Processes.

2012

[14] IRENA, "Renewable Energy Innovation Policy: Success Criteria and Strategies", March 2013, available online:

http://www.irena.org/publications/2013/Mar/Renewable-Energy-Innovation-Policy-Success-Criteria-and-Strategies

[15] DUPONT C, "The main biomass to energy routes", CEA Liten, 2014

[16] ATEE Association technique énergie environnement, Club biogaz, "Observatoire du biogaz en France", 2017, available online: http://atee.fr/biogaz/observatoire-du-biogaz-en-france

[17] GRDF, GRTgaz, le Syndicat des énergies renouvelables (SER), le SPEGNN et Teréga, 'Panorama du gaz renouvelable en 2018”, 2019

[18] Club Pyrogazéification - Filière "'Injection de biométhane de synthèse", "Position Paper de la filière, 'Injection de biométhane de synthèse" (issu de pyrogazéification)", 06/06/2018, $\mathrm{N}^{\circ}$ VERSION 20, available online: https://www.clubpyrogazeification.org/wpcontent/uploads/2018/10/Position-Paper-Fili\%C3\%A8re-Injection-de-biom\%C3\%A9thane-de-synth\%C3\%A8se-v21-clean.pdf

[19] HOLMGREN K,'Investment cost estimates for biomass gasification-based systems”, 2015

[20] European Technology and Innovation Platform Bioenergy, website: $h$ ttp://www.etipbioenergy.eu/?option=com content\&view=article\&id=280

[21] Project Gaya, website: http://www.projetgaya.com/

[22] Project Lahti Energy’s Kymijärvi II, website: https://www.lahtigasification.com/power-plant

[23] Project Gobigas, website: https://www.goteborgenergi.se/English

[24] Project bio SNG in Güssing, website: http://www.get.ac.at/pid_Ref_Bio-SNG_Tankstelle.html

[25] Project sundrop fuels, website: http://www.sundropfuels.com/

[26] Project fulcrum, website: www.fulcrum-bioenergy.com

[27] KERAMIDAS K et al., "Global Energy and Climate Outlook 2018: Sectoral mitigation options toward a low-emissions economy”, JRC Europa, 2018

[28] BAUER J et al., "Global energy sector emission reductions and bioenergy use: overview of the bioenergy demand phase of the EMF-33 model comparison”, Climatic Change, 2018

[29] IPCC, "Fifth Assessment Report (AR5)", 2014, available online: https://www.ipcc.ch/report/ar5/

[30] DESPRES J et al., "POLES-JRC model documentation”, JRC Europa, 2018

[31] LEPII, "POLES 5 - PROSPECTIVE Outlook on long-term energy systems", 2006

[32] IEA, “World Energy Outlook 2018”, 2018

[33] VALIN H et al., "Description of the GLOBIOM (IIASA) model and comparison with the MIRAGE-BioF (IFPRI) model”, Crops, 2013, available online: $\underline{w w w . i i a s a . a c . a t}$

[34] FUSS S et al., "Research priorities for negative emissions", 2016

[35] Conseil Mondial de l'Énergie et Conseil Français de l'Énergie, "Les Scénarios Mondiaux de l'Énergie à l'horizon 2050 - Mise en musique des futurs de l'énergie", 2013 
[36] THRAN D, "Milestones 2030, elements and milestones for the development of a stable and sustainable bioenergy strategy", DBFZ, UFZ Biomass energy use, 2015

[37] GUO M et al. "Bioenergy and biofuels: history, status and perspective", Renewable and Sustainable energy Reviews, 2014

[38] ADEME, "Le chauffage au bois, updated 03/05/2018, available online https://www.ademe.fr/particuliers-ecocitoyens/habitation/construire/chauffage-climatisation/chauffage-bois

[39] European commission, "EU Reference Scenario 2016, Energy, transport and GHG emissions, Trends to 2050", available online https://ec.europa.eu/clima/sites/clima/files/strategies/analysis/models/docs/20160712_summary_ref_scenario_en.pdf

[40] LAMBERT M, “Biogas: a significant contribution to decarbonizing gas markets?”, The Oxford institute for energy studies, June 2017, available online July 2017

[41] SPEIRS J. et al., “A Greener Gas Grid: What are the options?”, July 2017, Sustainable Gas Institute, Imperial College London, available at: http://www.sustainablegasinstitute.org/a-greener-gas-grid/

[42] IEA, “World Energy Outlook 2017 Excerpt - Outlook for Natural Gas”, May 2018, available online: https://webstore.iea.org/world-energyoutlook-2017-excerpt-outlook-for-natural-gas

[43] IEA, "How to guide for bioenergy, roadmap development and implementation", 2017, available online: https://www.iea.org/publications/freepublications/publication/technology-roadmap-how2guide-for-bioenergy.html

[44] LAMBERT M, "Power-to-Gas: Linking Electricity and Gas in a Decarbonizing World?", Oxford Institute for Energy Studies, October 2018

[45] ADEME, GRDF, GRTgaz, 'Un mix de gaz $100 \%$ renouvelable en 2050 ?’, janvier 2018

[46] JANCOVICI JM, “A quoi sert le gaz?”, August 2013, available online: https://jancovici.com/transition-energetique/gaz/a-quoi-sert-le-gaz/

[47] LI H and al., "Biomethane production via anaerobic digestion and biomass gasification", School of Business, Society and Engineering, Mälardalen University, Sweden, 2017

[48] GOTZ M et al., "Renewable Power-to-Gas: A technological and economic review", Renewable energy, January 2016

[49] ADEME, Enerdata, et Energies Demain, “'Actualisation du scénario énergie-climat - ADEME 2035-2050”, 2016 